\title{
Apolipoprotein E allelic variants and cerebral palsy
}

\author{
Evren Gümüşs ${ }^{1}$ Beyhan Durak Aras ${ }^{1}$, Oğuz Çilingirr ${ }^{1}$, Coşkun Yarar $^{2}$, Kürşat Bora Çarman², \\ Sibel Laçiner-Gürlevik ${ }^{2}$, Ozan Koçak ${ }^{2}$, Sevilhan Artan ${ }^{1}$ \\ Departments of ${ }^{1}$ Medical Genetics and ${ }^{2}$ Pediatrics, Osmangazi University, Faculty of Medicine, Eskisehir, Turkey. \\ E-mail: evreng@harran.edu.tr \\ Received: 14th November 2017, Revised: 25th December 2017, Accepted: 1st January 2018
}

SUMMARY: Gümüş E, Aras BD, Çilingir O, Yarar C, Çarman KB, LaçinerGürlevik S, Koçak O, Artan S. Apolipoprotein E allelic variants and cerebral palsy. Turk J Pediatr 2018; 60: 361-371.

Cerebral palsy (CP) is the most frequent cause of mobility restriction and posture disturbance in childhood. Against the complexity in disease etiology, genetic factors, including Apolipoprotein E allelic distribution in this patient population, are worthy targets for investigation. ApoE is a lipoprotein of central nervous system encoded by ApoE gene with its 3 main co-dominant alleles, 2, 3 and 4. We aimed to evaluate the allelic frequencies of ApoE gene and its association with coexisting clinical entities such as vision and hearing impairment, cognitive problems, seizures and MRI findings in a pediatric patient population native to middle Anatolian region. Seventy-eight children with CP and 60 healthy controls were genotyped. Genotypic variations along with coexisting clinical conditions and CP-related medical findings were compared between the patient and control groups. The Denver Developmental Screening Test for all, the Wechsler Intelligence Scale for Children-IV (short form WISC-IV; Turkish version) for the patients $>6 y$ and the Stanford-Binet Intelligence Scale (SB-5) for those who aged 2-6 years old were employed to evaluate cognitive and mental abilities of the patients. ApoE 2 and 4 alleles were more frequent in the patient group $(p<0.05)$, whereas ApoE 3 allele was more frequent in the healthy controls. ApoE 2/4 genotype has been determined $29 \%$ in the case group, but none in healthy control group. In the patient group with apolipoprotein 4 or 2 alleles, the rate of emergency cesarean section was found being significantly higher than the group with 3 allele. Brain MRI findings were not significantly different among ApoE allelic variants within the patient group. Our data show that the ApoE alleles may be effective in the development of cerebral palsy and may be associated with some clinical manifestations in those patients.

Keywords: cerebral palsy, apoE, neurodevelopment, GMFCS.

Cerebral palsy (CP) is a spectrum of diseases in the developing brain characterized with deterioration of neuromotor functions caused by a non-progressive disturbance during the early developmental period in affected children. Disturbance in motion and posture, communication difficulties, behavioral and cognitive problems and epileptic seizures are the main and typical clinical conditions commonly seen in CP patient, and the disease possess changeable features in phenotype by time. ${ }^{1}$ With the frequency of over 2 per 1000 live newborns, $\mathrm{CP}$ is the most common cause of neurological disability and activity-restriction in childhood. ${ }^{2,3}$ In different studies conducted between 1996 and 2009, the disease prevalence has been reported as $1.1-4.4 \%$ in Turkey. 4,5

$\mathrm{CP}$ is a multifactorial disease with diverse etiologic background consisting especially of prenatal and perinatal factors projecting a critical window of neuronal development. ${ }^{6}$ There is no decisive factor purely attributed to cause $\mathrm{CP}$, instead it is suggested that yet undefined, possibly multiple etiologic factors, in combination, may overwhelm the protective mechanisms of the brain during its developmental stage resulting in a range of motor and sensorial disintegration. ${ }^{7-9}$ Accelerated by the new era in genomic research sparked by revolutionary improvements in 
sequencing technologies, researchers affirmed that genetic variance might be underestimated in the propensity to have CP.10,11 What genetics factors are strongly associated with this debilitating disease are still of interest for many investigators including us. Although routine genetic testing is not recommended by published guidelines on diagnostic testing of CP, genetic studies in recent decades have mostly focused on determining copy number variants and single nucleotide differences in selected candidate genes between individuals for both attributing a genetic risk in children with $\mathrm{CP}$, and to make phenotype-genotype correlation in different clinical outcomes observed in seriously and mildly affected patients. ${ }^{11-13}$

ApoE is the core lipoprotein of central nervous system encoded by ApoE gene located on 19th chromosome. Three main co-dominant alleles, $\varepsilon 2, \varepsilon 3$ and $\varepsilon 4$, which are designated by SNPs at positions 112 and 158, are present for the gene. It is known that ApoE within neuronal cells plays important roles in cell repair mechanisms, lipid homeostasis and neurotransmission. ${ }^{14}$ In Alzheimer's disease, ApoE variants defined by certain nucleotide differences modulate the 3-dimentional structure of the protein, thus further mediating its functional attributes not just in brain development, but also in the recovery period of the developing brain after injury. ${ }^{15,16}$

There are many reports in the clinical literature making ApoE an important target in neurodevelopmental disease pathophysiology that its certain alleles have been associates with the degree of neurological involvement during the disease course. ${ }^{17-19}$ Early exposure of the

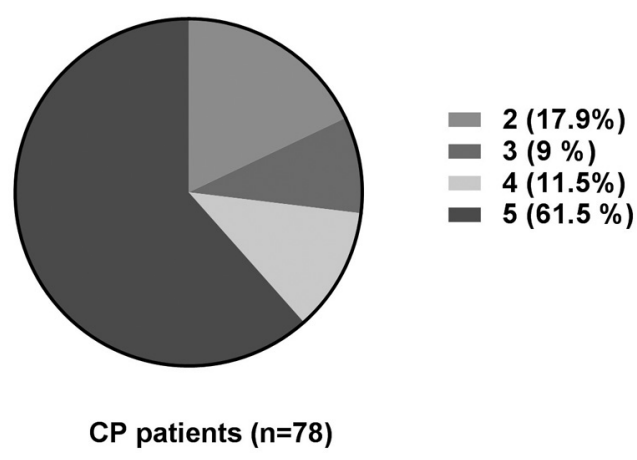

Fig. 1a. GMFCS Levels in CP patients immature brain to outside environment has been known to alter gene expression profile and brain structural development critically. ${ }^{20,21}$ After neurological stress factors like traumatic brain injury and hypoxia/ischemia, however, neurodevelopmental outcome has been found to be associated with ApoE alleles. ${ }^{22-24}$ Due to their potential effects in immature brain with various functions on neuronal repair and neuro-inflammation, those variants have been considered worthy for investigation in CP etiology. On the other hand, studies exist with inconclusive data remaining the relationship between $\mathrm{CP}$ and the certain ApoE alleles tenuous. In children with $\mathrm{CP}$, clinical observations have been proposed suggesting an unfavorable phenotypic effect regarding the ApoE $\varepsilon 4$ allele and a protective effect of the ApoE $\varepsilon 2$ and $\varepsilon 3$ alleles. ${ }^{25,26}$ On the contrary, negative effects of the $\varepsilon 4$ allele has not been proven with subsequent studies in CP children. ${ }^{27}$

In the current study, we aimed to readdress ApoE allelic variants and their role in $\mathrm{CP}$ etiology in a small Turkish cohort of CP patients in the light of demographic patient data, perinatal variables, CP-accompanying clinical conditions and neuroimaging findings.

\section{Material and Methods}

\section{Study Population and Exclusion Criteria}

The study recruited 78 children clinically diagnosed with $\mathrm{CP}$, and 60 sex- and age-matched control participants with no known neurologic disorder who applied to the child neurology outpatient clinic at Eskisehir Osmangazi University. Parents of all participants were given detailed information about the study, and CP evaluation questionnaires were applied (supplementary material). Informed consent

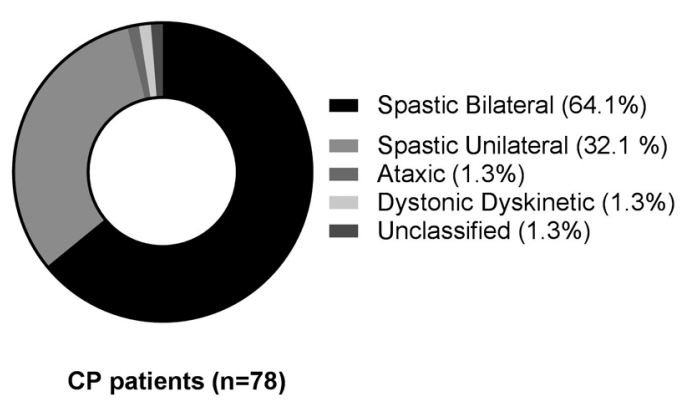

Fig. 1b. CP subtypes in CP patients 
was taken from the parents of the patients and the controls.

The diagnosis of CP was achieved clinically by an experienced child neurologist. ${ }^{28}$ Children with known genetic syndrome, chromosomal abnormality, clinically determined hypotonia, myopathy, and ataxia were excluded. All procedures were reviewed and approved by the Institutional Ethics Committee of the Eskisehir Osmangazi University according to the principles of the Declaration of Helsinki (2014-629).

\section{Variables}

In the clinical evaluation of $\mathrm{CP}$, gross motor functions including extent of intentional movements, posture and the requirement of mobility assistance are among the most important criteria. Diagnosis and clinical surveillance have been made depending on the level of gross motor functions and related scale. Prognosis depends not just on the gross motor skills and posture affected, but also on the concomitant factors in disease surveillance. According to the guidelines released by the network for the Surveillance of Cerebral Palsy in Europe (SCPE), CP is categorized under 4 main types as spastic unilateral, spastic bilateral, dyskinetic and ataxic along with unclassified or mixed type. ${ }^{29}$

The Gross Motor Function Classification System (GMFCS) 30 is one of the most convenient scales to evaluate functionality in CP under 5 levels in which the disease severity is related to higher numbers.

Mode and time of delivery, the presence of microcephaly, birth weight, MRI findings, eye problems and other variables included in $\mathrm{CP}$ evaluation form (Supp. 1) are also evaluated along with the above main parameters and genotype.

\section{Neurocognitive Evaluation and Brain Imaging}

The Denver Developmental Screening Test for all, The Wechsler Intelligence Scale for

Table I. Characteristics of Study Participants with or Without Cerebral Palsy (CP).

\begin{tabular}{|c|c|c|c|}
\hline Variable & $\mathrm{CP}(\mathrm{n}=78)$ & Control $(n=60)$ & $P$ value \\
\hline Age (median-25/75 p) & $6(4-10)$ & $5(3.2-7)$ & 0.056 \\
\hline Gender (boy/girl) & $45 / 33$ & $31 / 29$ & 0.495 \\
\hline Weight at birth (g) & & & $<0.001^{*}$ \\
\hline$<2000$ & 32 & 7 & \\
\hline $2000-3500$ & 36 & 39 & \\
\hline$>=3500$ & 10 & 14 & \\
\hline Head circumference at birth & & & $<0.001^{*}$ \\
\hline Microcephaly & 24 & 3 & \\
\hline Normal & 53 & 55 & \\
\hline Macrocephaly & 1 & 2 & \\
\hline Current head circumference & & & $<0.001^{*}$ \\
\hline Microcephaly & 24 & 0 & \\
\hline Normal & 52 & 54 & \\
\hline Macrocephaly & 2 & 6 & \\
\hline Gestational age in weeks & & & 0.25 \\
\hline$<37$ & 58 & 43 & \\
\hline$>=37$ & 20 & 17 & \\
\hline Mother's age at delivery & & & 0.095 \\
\hline$<=35$ & 73 & 50 & \\
\hline$>35$ & 5 & 10 & \\
\hline
\end{tabular}

$\mathrm{P}$ value from t-test and Chi-square test between groups. ${ }^{*} \mathrm{P}<0.001$ 
Children-IV (short form WISC-IV; Turkish version) for the patients $>6 y^{31}$ and The Stanford-Binet Intelligence Scale (SB-5) for those who were aged 2-6 years old ${ }^{32}$ were employed to evaluate cognitive and mental abilities of the patients.

MRI scans were performed on all children suspected with $\mathrm{CP}$ at the first admittance (Siemens Magnetom, 1.5 T, Siemens Healthcare, Germany). First MRI images, performed either in our hospital or any referring medical center, were attained from the medical records of the patients.

\section{Genotyping}

Venous blood samples were taken from patients and healthy controls, and genomic DNA extraction was carried out from $200 \mu \mathrm{l}$ of human whole blood by use of a commercially available DNA isolation kits in an automated extraction system from the same manufacturer (MagNA Pure Compact, Roche Diagnostics $\mathrm{GmbH})$. DNA concentration and quality were assessed spectrophotometrically (NanoDrop, Thermo Fisher, US), and DNA isolates were stored at -20 until analysis.

ApoE genotyping was performed via commercially available mutation detection kit (ApoE Mutation Detection Kit, LightCycler, Roche Diagnostics) by melting curve analysis via real-time PCR on a LightCycler Instrument (Roche Diagnostics) according to the method described by the manufacturer. In brief, hybridization probes specific for ApoE allelic variants (codon 112 and codon 158) in ApoE target amplicon were employed to discriminate three main genotypes in the basis of a difference in acquired melting curves during annealing phase. The method relies on a fluorescence resonance energy transfer system, and the genotypes, heterozygous or homozygous for each single nucleotide polymorphism, are attributed according to the certain melting temperatures (Tm) amplicons have.

\section{Statistics}

The categorical variables including sociodemographic characteristics were evaluated by Chi-Square tests, and the results were presented as frequency and percentage. Continuous variables were evaluated using Student t-test, and the results were displayed as median (Q1-Q3) or mean \pm standard deviation (SD). Distributions of continuous variables were tested by Shapiro Wilk test, and the parameters with non-Gaussian distribution were evaluated by Mann Whitney U test. The Hardy-Weinberg distributions of ApoE genotypes and genotype distributions between the patient group and the controls were tested by Chi-Square test. For better visualization, ApoE genotypes were stratified into three main representative alleles of $\varepsilon 2(\varepsilon 2 / \varepsilon 2 ; \varepsilon 2 /$ $\varepsilon 2), \varepsilon 3$ ( $\varepsilon 3 / \varepsilon 3$ only) and $\varepsilon 4$ (all other genotypes involving $\varepsilon 4$ ) for bivariate analysis of $\mathrm{CP}$ alleles with accompanying clinical conditions and perinatal pathologies as previously performed byKorja et al. ${ }^{22}$ Bivariate analysis was employed to evaluate the effect of having any ApoE genotypes on prediction of risk for developing $\mathrm{CP}$ and having other characteristics. Statistical elaboration was performed with statistical evaluation software SPSS v.21.0 (IBM Corp., Armonk, NY, USA).Statistical significance was defined as $\mathrm{P}<0.05$.

\section{Results}

The participants were evaluated for gender, age of mother at delivery, birth weight, head circumference at birth, current head circumference, findings related to perinatal

Table II. Association of MRI Findings with ApoE Alleles in CP Patients.

\begin{tabular}{lcccccccc}
\hline & $\begin{array}{c}\mathrm{CP} \\
(\mathrm{n}=78)\end{array}$ & $\begin{array}{c}\text { Percent } \\
(\%)\end{array}$ & $\begin{array}{c}\text { APO } \varepsilon 2 \\
(\varepsilon 2 / \varepsilon 2 ; \\
\varepsilon 2 / \varepsilon 3)\end{array}$ & $\begin{array}{c}\text { APO } \varepsilon 3 \\
(\varepsilon 3 / \varepsilon 3)\end{array}$ & $\begin{array}{c}\text { APO } \varepsilon 4 \\
(\text { all with } \varepsilon 4)\end{array}$ & $\chi 2$ & df & P-value \\
\hline MRI findings & & & & & & 9.36 & 6 & $\mathrm{~N}$ \\
PVL & 52 & $65.4 \%$ & 6 & 21 & 25 & & & \\
Myelination D. & 4 & $5.1 \%$ & 0 & 4 & 0 & & & \\
Cerebral atrophy & 11 & $14.1 \%$ & 0 & 8 & 3 & & & \\
Cortical Dys. & 11 & $14.1 \%$ & 2 & 5 & 4 & & & \\
\hline
\end{tabular}

Chi Square test. MRI: Magnetic Resonance Imaging, CP: Cerebral Palsy, Dys: Dysplasia

PVL: Periventricular Leucomalacia CI: confidence interval N: non informative 
Table III. Distribution of Genotype and Allele Frequencies of ApoE.

\begin{tabular}{lccccc}
\hline & Patient $(\mathrm{n}=78)$ & Control $(\mathrm{n}=60)$ & $\chi 2$ & $\mathrm{df}$ & P-value \\
\hline Genotypes & $2(3 \%)$ & $0(0 \%)$ & 6.74 & 7 & $\mathrm{~N}$ \\
$\varepsilon 2 / 2$ & $6(8 \%)$ & $12(20 \%)$ & & & \\
$\varepsilon 2 / 3$ & $23(29 \%)$ & $0(0 \%)$ & & \\
$\varepsilon 2 / 4$ & $38(49 \%)$ & $37(62 \%)$ & & \\
$\varepsilon 3 / 3$ & $8(10 \%)$ & $10(17 \%)$ & & \\
$\varepsilon 3 / 4$ & $1(1 \%)$ & $1(1 \%)$ & & \\
$\varepsilon 4 / 4$ & & & & \\
ApoE alleles & $8(10.25 \%)$ & $12(20 \%)$ & 9.31 & & \\
$\varepsilon 2$ & $38(48.71 \%)$ & $37(61.6 \%)$ & & & \\
$\varepsilon 3$ & $32(41.02 \%)$ & $11(18.3 \%)$ & & & \\
$\varepsilon 4$ & & & & \\
\hline
\end{tabular}

Chi Square test. Sig: Significance ${ }^{*} \mathrm{P}<0.01$

period, findings accompanying CP, GMFCS level, CP subtypes and brain MRI findings. The demographic data shown in Table I indicate that there were no significant differences between the patients with $\mathrm{CP}$ and controls regarding gender and median age. Median age for the patients group was 6 years, and the median age for the control group was 5 years. Median age of CP diagnosis for the patients was also 6 years old. Age of mother at delivery, gestational age, birth weight, atbirth and current head circumferences are displayed in Table I. Birth weight and head circumferences differed significantly between the patient and the control groups. Children with a birth weight below $2000 \mathrm{~g}$ had a 6.4 times higher risk for $\mathrm{CP}$ when compared to those with a birth weight over $3500 \mathrm{~g}$ (95\% CI: 2.02-20.25).

We observed that term children born after 37 weeks of gestation displayed decreased frequency of vision related problems $(\chi 2=6.26$; $\mathrm{df}: 2 ; \mathrm{p}=0.044)$. When we divide all infants into two groups based on their gestational age set to 37 weeks, prematurely born children displayed a slightly significant association with certain ApoE allele, ApoE4 ( $\mathrm{p}=0.048$; df:2; $\chi 2: 6.09$ ). When coexisting clinical entities displayed byCP patients were evaluated only the rate of speech disorders and hearing impairment significantly increased with advancing GMFCS levels $(\mathrm{p}=0.036)$

MRI findings in the case group consisted of periventricular leukomalacia with the rate of
$65.4 \%$, cerebral atrophy with $14.1 \%$, cortical dysplasia with $14.1 \%$ and myelination problem with $5.1 \%$ (Table II). Due to low representation of individuals for each allelic group, statistical calculation could not be performed. It was interesting to see that Apo $\varepsilon 3$ group, commonly considered as the native allele, was the only one displaying myelination problems in MRI (TableII).

Genotyping data were assessed and the distribution of ApoE alleles and genotypes in the study population was displayed in the table (TableIII). Observed allele frequencies were found to be in Hardy-Weinberg equilibrium. The distribution of ApoE alleles $\varepsilon 2, \varepsilon 3$ and $\varepsilon 4$ was statistically significant between the control and patient groups $(\chi 2=9.31 ; \mathrm{df}=2 ; \mathrm{p}=0.002)$. Observed odds ratios of ApoE $\varepsilon 2$ and ApoE \&3 alleles were 2.64 and 3.27, respectively. Strikingly, possession of the ApoE $\varepsilon 4$ allelic variant was associated with a 14.5 times higher risk for $\mathrm{CP}$ in comparision to those possessing a different allele.

ApoE allelic variants did not exhibit statistically significant difference with GMFCS levels (Suppl. 2 ), clinical entities accompanying $\mathrm{CP}$ (Table IV), CP subtypes (Table V) and neuroimaging findings (Table II) when compared among the allelic groups. Patients possessing $\varepsilon 4$ allele seemed to have higher rates of preeclampsia than those not possessing the same allele, but statistical significance was not achieved. The patients who possess ApoE \&4 allele have statistically increased rates of undergoing 
emergency cesarean section when compared to the patients carrying another allele $(\mathrm{p}=0.018)$. ApoE $\varepsilon 3$ allele here seemed to have a protective effect for emergency cesarean delivery (Table IV).

\section{Discussion}

Cerebral palsy is a nonprogressive but changeable posture and movement disorder characterized with persistent, activity-restricting loss of motor functions caused by damage to the developing brain. A number of studies with large population size reported spastic $\mathrm{CP}$ as the most common type worldwide with the rates between $89-94 \% .33,34$ Spastic type constitutes $96 \%$ of the patients with CP as coherent with the literature. Among those, spastic bilateral is the leading type of the spastic group commonly seen in the patients according to the classification recommended by SCPE. ${ }^{33}$ In a study from Denmark, Toppet al. ${ }^{23}$ reported the most common type of $\mathrm{CP}$ as spastic bilateral type with a ratio of $65 \%$. Ipek et $a .^{36}$ reported national data on $\mathrm{CP}$

Table IV. Association of Perinatal Pathologies and Coexisting Clinical Entities with ApoE Alleles in CP.

\begin{tabular}{|c|c|c|c|c|c|c|}
\hline & $\begin{array}{c}\text { APO } \varepsilon 2 \\
(\varepsilon 2 / \varepsilon 2 ; \varepsilon 2 / \varepsilon 3)\end{array}$ & $\begin{array}{c}\mathrm{APO} \varepsilon 3 \\
(\varepsilon 3 / \varepsilon 3)\end{array}$ & $\begin{array}{c}\text { APO } \varepsilon 4 \\
\text { (all with } \varepsilon 4 \text { ) }\end{array}$ & $\chi^{2}$ & $\mathrm{df}$ & P-value \\
\hline Variable (78 children) & $\mathrm{n}$ & $\mathrm{n}$ & $\mathrm{n}$ & & & \\
\hline \multicolumn{7}{|l|}{ Gender } \\
\hline Boy & 2 & 25 & 18 & 4.55 & 2 & 0.103 \\
\hline Girl & 6 & 13 & 14 & & & \\
\hline \multicolumn{7}{|l|}{ Emergency C. Section } \\
\hline Yes & 3 & 6 & 15 & 8.07 & 2 & $0.018 *$ \\
\hline No & 5 & 32 & 17 & & & \\
\hline \multicolumn{7}{|l|}{ Preeclampsia } \\
\hline Yes & 0 & 1 & 4 & 3.43 & 2 & $\mathrm{~N}$ \\
\hline No & 8 & 37 & 28 & & & \\
\hline \multicolumn{7}{|l|}{ Asphyxia } \\
\hline Yes & 1 & 13 & 9 & 1.54 & 2 & 0.461 \\
\hline No & 7 & 25 & 23 & & & \\
\hline \multicolumn{7}{|l|}{ Seizures } \\
\hline Yes & 6 & 24 & 18 & 1.03 & 2 & 0.597 \\
\hline No & 2 & 14 & 14 & & & \\
\hline \multicolumn{7}{|l|}{ Vision Problems } \\
\hline Yes & 3 & 13 & 14 & 0.67 & 2 & 0.715 \\
\hline No & 5 & 25 & 18 & & & \\
\hline \multicolumn{7}{|c|}{ Speech-Hearing Problems } \\
\hline Yes & 6 & 18 & 18 & 2.15 & 2 & 0.34 \\
\hline No & 2 & 20 & 14 & & & \\
\hline \multicolumn{7}{|l|}{ Learning Problems } \\
\hline Yes & 5 & 22 & 15 & 1.12 & 2 & 0.572 \\
\hline No & 3 & 16 & 17 & & & \\
\hline Birth Weight & & & & 7.72 & 6 & 0.102 \\
\hline$<2000 \mathrm{~g}$ & 2 & 11 & 19 & & & \\
\hline 2000-3500g & 5 & 21 & 10 & & & \\
\hline$>=3500 \mathrm{~g}$ & 1 & 6 & 3 & & & \\
\hline Gestational age (wk) & & & & 6.18 & 4 & 0.186 \\
\hline$<=28$ & 1 & 5 & 5 & & & \\
\hline 29-36 & 3 & 21 & 23 & & & \\
\hline$>=37$ & 4 & 12 & 4 & & & \\
\hline
\end{tabular}


types defining spastic bilateral $\mathrm{CP}$ as the most prevalent type with $67 \%$.Consistent with those data, our study reported the most common type of $\mathrm{CP}$ with the ratio of $64 \%$ as spastic bilateral type.

The male to female ratio of patients with $\mathrm{CP}$ in the study was 1.36 , this incidence rate is similar to the literature indicating prevalent nature of $\mathrm{CP}$ in males regionally. Although there is no clear evidence indicating an effect of gender on clinical severity and prognosis of $\mathrm{CP}$, male sex is imposing a higher risk to have CP especially in preterm infants. ${ }^{37,38}$ Attributed high risk for male fetal sex seem to be related to the fact that spontaneous prematurity occurs more frequently in males regardless of membrane integrity in Europe. ${ }^{39}$

Birth weight is an important modifier in predicting $\mathrm{CP}$ risk, since low birth weight is associated with increased risk for CP.40Instead of determining a pediatric norm of $2500 \mathrm{~g}$ for the cut-off value for low birth weight, this study set the value as $2000 \mathrm{~g}$, which is the average weight of infants in the moderately low birth weight group, this is similar to the study conducted by $\mathrm{Wu}$ et al. ${ }^{41}$ In studies from Norway, Scotland and Iceland, 47-56\% of CP patients have low birth weight. ${ }^{42,43}$ In this study, patients with low birth weight constituted $41 \%$ of the all patients, which is a relatively lower rate when compared to the literature. For the study, a lower cut-off value could be predetermined, but we used this cutoff limit to eliminate the bias brought to the study due to patient stratification during the application process. A group of our patients represent advanced stage $\mathrm{CP}$ cases requiring advanced surveillance and support with critical problems at birth.

Microcephaly is an expected outcome for CP when the patients with CP have been investigated for brain development. ${ }^{44}$ In the literature, Kuroda et al. ${ }^{45}$ reported microcephaly as $21 \%$ in their study. In concordance with the national literature, $31 \%$ of our patient population was born with microcephaly.

Seizures are among crucial symptoms frequently seen in CP patients with a ratio of $15-60 \% .{ }^{46} \mathrm{In}$ a study with a relatively small sample size, seizures were reported in more than $80 \%$ of the patients with CP. ${ }^{47}$ Zaferiouet al. ${ }^{48}$ defined epilepsy in slightly over than $36 \%$ of the patients in $\mathrm{CP}$ group as overall incidence regardless of the level of extremity paralysis. ${ }^{48}$ We defined convulsive attacks as those that occurred at any period during follow-up and the prevalence was $62 \%$ in this study, which is considered in the high range of the literature. Reports from the literature display a trend in increasing epilepsy rates in the patients with CP having increased paralysis state. ${ }^{46,48}$

Language and vision problems as well as hearing impairment are quite common in patients with $\mathrm{CP}$ due to the defects in neurodevelopment. The percentage of problems in language and hearing has been reported as $54 \%$ of CP patients in this study, which is consistent with the literature giving the same range between $28-60 \% .{ }^{49}$ Diagnosis and treatment of visionrelated problems are of importance due to favorable effects and direct impact of normal vision on the routine activities of children with CP in daily life and the success rate from special education and rehabilitation programs, respectively. ${ }^{50}$ Vision problems are present in a range of $10-50 \%$ of the $\mathrm{CP}$ patients in literature. Singhiet al..$^{51}$ reported any vision problem in $41 \%$ of their patients. We report here that vision problems were present in $39 \%$ of the patients recruited in this study.

Learning difficulties and behavioral problems are more common in this group of children in comparison to those in the normal population with a prevalence of about $25 \% .{ }^{52}$ In the

Table V. Association of CP subtypes with ApoE alleles in CP patients Cerebral Palsy subtypes

\begin{tabular}{lcccccccc}
\hline ApoE alleles & SB & SU & A & DD & UC & $\chi 2$ & df & P-value \\
\hline$\varepsilon 2$ & 4 & 3 & 0 & 1 & 0 & 12.7 & 8 & $\mathrm{~N}$ \\
$\varepsilon 3$ & 23 & 14 & 0 & 0 & 1 & & & \\
$\varepsilon 4$ & 23 & 8 & 1 & 0 & 0 & & & \\
\hline
\end{tabular}

Chi Square test. SB: spastic bilateral, SU: spastic unilateral, A: ataxic, DD: dystonic dyskinetic, UC: unclassified. N: non informative 
patient group on which we have conducted our study, behavioral and learning problems constitute $53 \%$ of all patients. Increased rate of those problems in our study group could be explained by the small population size, complicated patients referred for advanced medical care to our institution and relatively insufficient rehabilitation programs offered to the patients.

Asphyxia is known as the most critical factor for development of CP especially during the perinatal-period. Various studies originated in Turkey have shown that roughly one third of patients with $\mathrm{CP}$ have asphyxia in retrieved medical histories. Ones et al. ${ }^{34}$ found that $41 \%$ of CP patients had asphyxia, while Erkin et al. ${ }^{5}$ reported the same parameter as $35 \%$ in their study conducted on 625 cases with CP. In this study, $30 \%$ of the patients have a history of asphyxia, which is lower than expected. It could be speculated that improved pregnancy care in perinatal period and advanced technology enabled to have ameliorated rates of asphyxia and related complications in recent years. ${ }^{2}$

Brain MRI is the most beneficial imaging tool commonly used in order to evaluate brain structure as well as to search for etiological factors in CP. Many clinical studies conducted in children with CP showed that at least one pathological finding exists in $75-93 \%$ of acquired brain MRI. ${ }^{52,53}$ We have reported this rate as $98 \%$ in the current study, which is quite high when compared to the literature. High rate of the presence of an abnormal finding in brain MRI could be explained with our patient profile mostly represented by spastic type $\mathrm{CP}$, a group of patients mostly accompanied by brain changes in MRI. Frequently seen pathologies diagnosed by MRI in CP are periventricular leukomalacia (PVL) at most and cerebral atrophy. ${ }^{54}$ In parallel with the literature, we described PVL and cerebral atrophy as the leading positive findings in the patients. Interestingly, Towsleyet al. ${ }^{55}$ reported positive correlation between GMFCS levels of the patients with $\mathrm{CP}$ and MRI findings. We did not determine any correlation between MRI findings and GMCSF levels of the children with CP. In this study, the most common MRI lesion for all GMCSF levels in the patients was PVL. Subjective criteria exist in evaluation of patients with $\mathrm{CP}$ based on gross motor functions, and GMFCS categorization works depending on those findings attained by medical evaluation. Thus, it is quite difficult to reach a consensus among different institutions on GMFCS classification. It is still quite necessary and critical for physicians to employ GMFCS categories for better surveillance of patients with CP. Evaluation and clinical classification of functional conditions of the patients with CP on the basis of GMFCS are of importance for both providing better medical surveillance and planning necessary supportive approaches. Andersen et al. ${ }^{42}$ reported that $28 \%$ of the patients were at levels 4 and 5 . Based on the gross motor functions, $27 \%$ of the patients were at GMFCS levels 1, 2 and 3, 73\% were at levels 4 and 5 in this study, a significantly high rate for that level. There are many factors that may have had apotential impact on this impressive result. Referral of the complicated patients to our institution, a university hospital, and insufficient care in physical therapy given to those patients due to regional difficulties could be primary reasons.

ApoE is one of the main apolipoproteins of central neuronal system playing important roles in neurobiology. In several studies conducted in different populations, association was shown between $\varepsilon 2$ allele and CP. ${ }^{56,57}$ In those studies, it was also reported that normal birth weight introduced protective effect in children against $\mathrm{CP}$ with an odds ratio of 4-10. In the current study, data displayed that normal birth weight is protective for 6.4 times against CP development which is coherence with the literature. The lack of an association between CP subtypes and ApoE genotypes was reported in a number of studies as well. ${ }^{56,58}$ The results of our study suggested that there was no significant association between CP subtypes and ApoE genotypes as well. To be noted here, our data is informative only for the most frequently represented CP subtypes in the study including spastic unilateral or bilateral CP.

Between the ApoE $\varepsilon 4$ allele and CP, the existence of an association was defined in many studies. ${ }^{48,59}$ Moreover, Kuroda et al. ${ }^{48}$ reported that there is an association between CP and both the $\varepsilon 2$ and $\varepsilon 4$ alleles.In their study, 209 CP patients and 209 sex- and age-matched healthy controls were evaluated, and genotyping data suggested that $\varepsilon 4$ allele render 3.4 times and 
higher risk for $\mathrm{CP}$ to those possessing it. Our study revealed that the $\varepsilon 2$ allele elevates $\mathrm{CP}$ risk slightly, whereas $\varepsilon 4$ allele increases the disease risk about 3 times. A similar trend was seen with the $\varepsilon 4$ allele carriers in those populations. Relatively lower odds ratio determined in this study could be due to population characteristics regarding the $\varepsilon 2$ allele distribution. Another study that determined no association between ApoE alleles and CP risk was conducted by McMicheal et al., ${ }^{60}$ additionally reporting an association between $\varepsilon 2$ allele and low birth weight as well as prematurity.

Disturbance in neurobehavioral functions and brain healing process along with reduced ischemia tolerance have all been implicated with possessing the ApoE $\varepsilon 4$ allele in a number of studies. ${ }^{27,61}$ Interestingly, against poor prognosis and unfavorable clinical outcome stemmed from $\varepsilon 4$ allele, some studies suggest that having the ApoE $\varepsilon 3$ allele renders favorable response to traumatic and hypoxic injury in developing brain. ${ }^{62}$ In conjunction with those studies, two recent studies conducted by Lien et al. ${ }^{63,64}$ reported that the ApoEq4 allele was associated with CP and its clinical surveillance along with poor prognosis in children. In another study from the same group, no association was determined between the ApoE alleles and GMFCS levels. ${ }^{25}$ Accordingly, we did not find any association between the ApoE allelic variants and GMFCS levels in the patients with $\mathrm{CP}$.

We evaluated ApoE alleles and their association with the most relevant variables in clinical surveillance of patients with $\mathrm{CP}$ including GMFCS levels, perinatal events such as asphyxia, meconium aspiration and preeclampsia, postnatal coexisting conditions involving convulsions, speech and hearing problems and newborn parameters along with mother's gestational history in the current study. The main limitations of the study are relatively small sample size recruited in the study, employment of a case-control setting, which renders data open to population stratification, and possible but predictable stratification in patient sampling owing to the hospital setting, that is being a tertiary referral hospital increases the rate of complicated cases applied and more severe disease progress requiring advanced patient care. All study participants have a shared origin of Caucasians native to middle Anatolia suggesting regioncentric frequency of target alleles. Further studies with larger sample cohort from the same geographical region are required to validate these results. Another critical point is related to the heterogeneous nature of $\mathrm{CP}$ regarding various pathophysiological factors involving genetic, environmental and unknown variables residing at the background. In the current study, ApoE alleles have been selected to be tested but many other genetic factors, either concomitantly as individual modifiers or together as haplotypes may be involved in the clinical scenario. In central Anatolia, ApoE $\varepsilon 4$ represents the risk allele to have $\mathrm{CP}$ in study population formed of the patients with GMFCS level 5 in majority represented with leading MRI finding of PVL, but GMFCS level and $A p o E$ allele did not show any association. ApoE $\varepsilon 2 / \varepsilon 4$ genotype was not represented in the control group. Those study outcomes need to be affirmed in further studies with recruitment of larger, independent study participants.

\section{Acknowledgement}

We cordially thank all the children and their families who contributed to the study.

\section{Supplementary data is available at:}

http://www.turkishjournalpediatrics.org/ uploads/turkjped.2018.04.002.S1.pdf

\section{REFERENCES}

1. Rosenbaum P, Paneth N, Leviton A, et al. A report: The definition and classification of cerebral palsy April 2006. Dev Med Child Neurol Suppl 2007; 109: 8-14.

2. Van Naarden Braun K, Doernberg N, Schieve L, Christensen D, Goodman A, Yeargin-Allsopp M. Birth Prevalence of Cerebral Palsy: A Population-Based Study. Pediatrics 2016; 137. doi: 10.1542/peds.2015-2872.

3. Himmelmann K, Uvebrant P. The panorama of cerebral palsy in Sweden. XI. Changing patterns in the birth-year period 2003-2006. Acta Paediatr 2014; 103: 618-624.

4. Aydin R. Serebral palsi epidemiyolojisi. Türkiye Klinikleri Fiziksel Tip ve Rehabilitasyon Dergisi Özel Sayıs1 2009; 2: 1-7.

5. Erkin G, Delialioglu SU, Ozel S, Culha C, Sirzai H Risk factors and clinical profiles in Turkish children with cerebral palsy: Analysis of 625 cases. Int J Rehabil Res 2008; 31: 89-91.

6. Badawi N, Keogh JM. Causal pathways in cerebral palsy. J Paediatr Child Health 2013; 49: 5-8. 
7. Numata Y, Onuma A, Kobayashi Y, et al. Brain magnetic resonance imaging and motor and intellectual functioning in 86 patients born at term with spastic diplegia. Dev Med Child Neurol 2013; 55: 167-172.

8. Himmelmann K, Hagberg G, Uvebrant P. The changing panorama of cerebral palsy in Sweden. X. Prevalence and origin in the birth-year period 1999-2002. Acta Paediatr 2010; 99: 1337-1343.

9. MacLennan AH, Thompson SC, Gecz J. Cerebral palsy: Causes, pathways, and the role of genetic variants. Am J Obstet Gynecol 2015; 213: 779-788.

10. Costeff H. Estimated frequency of genetic and nongenetic causes of congenital idiopathic cerebral palsy in west Sweden. Ann Hum Genet 2004; 68(Pt 5): $515-520$.

11. Fahey MC, Maclennan AH, Kretzschmar D, Gecz C, Kruer MC. The genetic basis of cerebral palsy. Dev Med Child Neurol 2017; 59: 462-469.

12. Oskoui M, Gazzellone MJ, Thiruvahindrapuram B, et al. Clinically relevant copy number variations detected in cerebral palsy. Nat Commun 2015; 6: 7949.

13. Wu D, Zou YF, Xu XY, et al. The association of genetic polymorphisms with cerebral palsy: A meta-analysis. Dev Med Child Neurol 2011; 53: 217-225.

14. Cedazo-Mínguez A. Apolipoprotein E and Alzheimer's disease: Molecular mechanisms and therapeutic opportunities. J Cell Mol Med 2007; 11: 1227-1238.

15. Mahley RW, Weisgraber KH, Huang Y. Apolipoprotein E4: A causative factor and therapeutic target in neuropathology, including Alzheimer's disease. Proc Natl Acad Sci U.S.A 2006; 103: 5644-5651.

16. Ponsford J, McLaren A, Schönberger M, et al. The association between apolipoprotein $\mathrm{E}$ and traumatic brain injury severity and functional outcome in a rehabilitation sample. J Neurotrauma 2011; 28: 16831692.

17. Sriram S, Rodriguez M. Indictment of the microglia as the villain in multiple sclerosis. Neurology 1997; 48: $464-470$.

18. Winter S, Autry A, Boyle C, Yeargin-Allsopp M. Trends in the prevalence of cerebral palsy in a populationbased study. Pediatrics 2002; 110: 1220-1225.

19. de Kieviet JF, Zoetebier L, van Elburg RM, Vermeulen RJ, Oosterlaan J. Brain development of very preterm and very low-birthweight children in childhood and adolescence: A meta-analysis. Dev Med Child Neurol 2012; 54: 313-323.

20. Haldipur P, Bharti U, Alberti C, et al. Preterm delivery disrupts the developmental program of the cerebellum. PLoS One 2011; 6: e23449.

21. Greisen G. To autoregulate or not to autoregulate-that is no longer the question. Semin Pediatr Neurol 2009; 16: 207-215.

22. Korja M, Ylijoki M, Lapinleimu H, et al. Apolipoprotein $\mathrm{E}$, brain injury and neurodevelopmental outcome of children. Genes Brain Behav 2013; 12: 348-352.
23. Norda S, Rausch TK, Orlikowsky T, et al. Apolipoprotein E genotype in very preterm neonates with intrauterine growth restriction: An analysis of the German Neonatal Network Cohort. Biomed Res Int 2017; 2017: 2837027.

24. Laskowitz DT, Horsburgh K, Roses AD. Apolipoprotein $\mathrm{E}$ and the CNS response to injury. J Cereb Blood Flow Metab 1998; 18: 465-471

25 Lien E, Andersen GL, Bao Y, et al. Apolipoprotein E polymorphisms and severity of cerebral palsy: A cross-sectional study in 255 children in Norway. Dev Med Child Neurol 2013; 55: 372-377.

26. Xu Y, Wang $\mathrm{H}$, Sun $\mathrm{Y}$, et al. The association of apolipoprotein E gene polymorphisms with cerebral palsy in Chinese infants. Mol Genet Genomics 2014; 289: 411-416.

27. Stoknes M, Lien E, Andersen GL, et al. Child apolipoprotein $\mathrm{E}$ gene variants and risk of cerebral palsy: Estimation from case-parent triads. Eur J Paediatr Neurol2015; 19: 286-291.

28. Washburn LK, Dillard RG, Goldstein DJ, Klinepeter KL, deRegnier RA, O'Shea TM. Survival and major neurodevelopmental impairment in extremely low gestational age newborns born 1990-2000: A retrospective cohort study. BMC Pediatr 2007; 7:20.

29. Christine C, Dolk H, Platt MJ, Colver A, Prasauskiene A, Krägeloh-Mann I; SCPE Collaborative Group. Recommendations from the SCPE collaborative group for defining and classifying cerebral palsy. Dev Med Child Neurol Suppl 2007; 109: 35-38.

30. Palisano R, Rosenbaum P, Walter S, Russell D, Wood E, Galuppi B. Development and reliability of a system to classify gross motor function in children with cerebral palsy. Dev Med Child Neurol 1997; 39: 214-223.

31. Crawford JR, Anderson V, Rankin PM, Macdonald J. An index-based short-form of the WISC-IV with accompanying analysis of the reliability and abnormality of differences. Br J Clin Psychol 2010; 49(Pt 2): 235258.

32. Yin Foo R, Guppy M, Johnston LM. Intelligence assessments for children with cerebral palsy: A systematic review. Dev Med Child Neurol 2013; 55: 911-918.

33. Johnson A, Perinatal N, Unit E, Road O. Prevalence and characteristics of children with cerebral palsy in Europe. Dev Med Child Neurol 2002; 44: 633-640.

34.Ones K, Celik B, Caglar N, Gultekin O, Yilmaz E, Cetinkaya B. Serebralpalsi polikliniğine müracaat eden hastaların demo grafik ve klinik özellikleri. Türkiye Fiziksel Tip ve Rehabilitasyon Dergisi 2008; 54: 13-16.

35. Topp M, Uldall P, Greisen G. Cerebral palsy births in eastern Denmark, 1987-90: Implications for neonatal care. Paediatr Perinat Epidemiol2001; 15: 271-277.

36. Ipek B, Ecevit C, Ipek I, Kocabas O, Kavaklı T, Ozturk A. The evaluation of 371 cases with cerebral palsy between January 1984 and December 2004. J Neurol Sci 2007; 24: 270-279. 
37. Romeo DM, Sini F, Brogna C, Albamonte E, Ricci D, Mercuri E. Sex differences in cerebral palsy on neuromotor outcome: A critical review. Dev Med Child Neurol 2016; 58: 809-813.

38. Johnston MV, Hagberg H. Sex and the pathogenesis of cerebral palsy. Dev Med Child Neurol 2007; 49: 74-78.

39. Peelen MJ, Kazemier BM, Ravelli AC, et al. Impact of fetal gender on the risk of preterm birth, a national cohort study. Acta Obstet Gynecol Scand 2016; 95 : 1034-1041.

40. Himpens E, Van Den Broeck C, Oostra A, Calders P, Vanhaesebrouck P. Prevalence, type, distribution, and severity of cerebral palsy in relation to gestational age: A meta-analytic review. Dev Med Child Neurol 2008; 50: $334-340$

41. Wu YW, Croen LA, Torres AR, Van De Water J, Grether JK, Hsu NN. Interleukin-6 genotype and risk for cerebral palsy in term and near-term infants. Ann Neurol 2009; 66: 663-670.

42. Andersen GL, IrgensLM,Haagaas I, Skranes JS, Meberg AE, Vik T. Cerebral palsy in Norway: Prevalence, subtypes and severity. Eur J Paediatr Neurol 2008; 12: $4-13$.

43. Sigurdardóttir S, Thórkelsson T, Halldórsdóttir M, Thorarensen O, Vik T.Trends in prevalence and characteristics of cerebral palsy among Icelandic children born 1990 to 2003. Dev Med Child Neurol 2009; 51: 356-563.

44. Pharoah PO, Cooke T, Johnson MA, King R, Mutch L. Epidemiology of cerebral palsy in England and Scotland, 1984-9. Arch Dis Child Fetal Neonatal Ed 1998; 79: F21-F25.

45. Kuroda MM, Weck ME, Sarwark JF, Hamidullah A, Wainwright MS. Association of apolipoprotein E genotype and cerebral palsy in children. Pediatrics 2007; 119: 306-313.

46. Kulak W, Sobaniec W. Risk factors and prognosis of epilepsy in children with cerebral palsy in north-eastern Poland. Brain Dev 2003; 25: 499-506.

47. Bruck I, Antoniuk SA, Spessatto A, Bem RS, Hausberger $\mathrm{R}$, Pacheco CG. Epilepsy in children with cerebral palsy. Arq Neuropsiquiatr 2001; 59: 35-39.

48. ZafeiriouDI, Kontopoulos EE, Tsikoulas I. Characteristics and prognosis of epilepsy in children with cerebral palsy. J Child Neurol 1999; 14: 289-294.

49. Ukhanova TA, Gorbunov FE, Ivanova VV. Reflexotherapy combined with cortexin in the complex treatment of speech disorders in patients with cerebral palsy. Zh Nevrol Psikhiatr Im SS Korsakova 2011; 111( Pt 1): 19-22.

50. Duman O, İmad FM, Kizilay F, Yucel I, Balkan S, Haspolat S. Serebralpalsili hastaların işlevsel kapasitelerine göre görme sorunlarının değerlendirilmesi. Çocuk Sağlığı ve Hastalıkları Dergisi 2005; 48:130-135.
51. Singhi PD, Ray M, Suri G. Clinical spectrum of cerebral palsy in North India--an analysis of 1,000 cases. J Trop Pediatr 2002; 48: 162-166.

52. Parkes J, White-Koning M, Dickinson $\mathrm{HO}$, et al Psychological problems in children with cerebral palsy: A cross-sectional European study. J Child Psychol Psychiatry 2008; 49: 405-413.

53. Adın S, Aslan M, Doğan M, Yakıncı C, Alkan A. Term ve preterm serebralpalsili çocuklarda etiyoloji, klinik ve manyetik rezonans görüntüleme bulguları. İnönü Üniversitesi Tıp Fakültesi Dergisi2009; 6: 169-172.

54. Krägeloh-Mann I, Petersen D, Hagberg G, Vollmer B, Hagberg B, Michaelis R. Bilateral spastic cerebral palsy--MRI pathology and origin. Analysis from a representative series of 56 cases. Dev Med Child Neurol 1995; 37: 379-397.

55. Towsley K, Shevell MI, Dagenais L; REPACQ Consortium. Population-based study of neuroimaging findings in children with cerebral palsy. Eur J PaediatrNeurol 2011; 15: 29-35.

56. Braga LW, Borigato EVM, Speck-Martins CE, et al Apolipoprotein E genotype and cerebral palsy. Dev Med Child Neurol 2010; 52: 666-671.

57. Lawson RD, Badawi N. Etiology of cerebral palsy. Hand Clin 2003; 19: 547-556.

58. Odding E, Roebroeck M, Stam H. The epidemiology of cerebral palsy: Incidence, impairments and risk factors. Disabil Rehabil 2006; 28: 183-191.

59. Harhangi BS, de Rijk MC, van Duijn CM, Van Broeckhoven C, Hofman A, Breteler MM. APOE and the risk of $\mathrm{PD}$ with or without dementia in a populationbased study. Neurology 2000; 54: 1272-1276.

60. McMichael GL, Gibson CS, Goldwater PN; South Australian Cerebral Palsy Research Group. Association between Apolipoprotein E genotype and cerebral palsy is not confirmed in a Caucasian population. Hum Genet 2008; 124: 411-416.

61. Kim J, Basak JM, Holtzman DM. The role of apolipoprotein E in Alzheimer's disease. Neuron 2009; 63: 287-303.

62. Lo TYM, Jones PA, Chambers IR, et al. Modulating effect of apolipoprotein E polymorphisms on secondary brain insult and outcome after childhood brain trauma. Child's Nerv Syst 2009; 25: 47-54.

63. Lien E, Andersen GL, Bao Y, et al. Gene sequences regulating the production of apoE and cerebral palsy of variable severity. Eur J Paediatr Neurol 2014; 18: 591-596.

64. Lien E, Andersen G, Bao Y, et al. Genes determining the severity of cerebral palsy: the role of single nucleotide polymorphisms on the amount and structure of apolipoprotein E. Acta Paediatr 2015; 104: 701-706. 